\title{
Linkage of national soil quality measurements to primary care medical records in England and Wales: a new resource for investigating environmental impacts on human health
}

\author{
Jack E. Gibson $^{1 *}$ (D) E. Louise Ander², Mark Cave ${ }^{3}$, Fiona Bath-Hextall ${ }^{4}$, Anwar Musah $^{1}$ and Jo Leonardi-Bee ${ }^{1}$
}

\begin{abstract}
Background: Long-term, low-level exposure to toxic elements in soil may be harmful to human health but large longitudinal cohort studies with sufficient follow-up time to study these effects are cost-prohibitive and impractical. Linkage of routinely collected medical outcome data to systematic surveys of soil quality may offer a viable alternative.

Methods: We used the Geochemical Baseline Survey of the Environment (G-BASE), a systematic X-ray fluorescence survey of soil inorganic chemistry throughout England and Wales to obtain estimates of the concentrations of 15 elements in the soil contained within each English and Welsh postcode area. We linked these data to the residential postcodes of individuals enrolled in The Health Improvement Network (THIN), a large database of UK primary care medical records, to provide estimates of exposure. Observed exposure levels among the THIN population were compared with expectations based on UK population estimates to assess representativeness.

Results: Three hundred seventy-seven of three hundred ninety-five English and Welsh THIN practices agreed to participate in the linkage, providing complete residential soil metal estimates for $6,243,363$ individuals ( $92 \%$ of all current and former patients) with a mean period of prospective computerised medical data collection (follow-up) of 6.75 years. Overall agreement between the THIN population and expectations was excellent; however, the number of participating practices in the Yorkshire \& Humber strategic health authority was low, leading to restricted ranges of measurements for some elements relative to the known variations in geochemical concentrations in this area.
\end{abstract}

Conclusions: The linked database provides unprecedented population size and statistical power to study the effects of elements in soil on human health. With appropriate adjustment, results should be generalizable to and representative of the wider English and Welsh population.

Keywords: Environment and public health [N06], Residence characteristics [N06.850.505.400.800], Catchment area (health) [N06.850.505.400.800.200], Soil [D20.721] [G01.311.820] [N06.230.600], Elements [D01.268], Medical record linkage [E05.318.308.940.968], Epidemiologic methods [N06.850.520], Censuses [N06.850.505.400.225], England [Z01.639.280.300], Wales [Z01.639.280.914]

\footnotetext{
* Correspondence: jack.gibson@nottingham.ac.uk

${ }^{1}$ Division of Epidemiology \& Public Health, School of Medicine, University of Nottingham, Clinical Sciences Building Phase II, City Hospital, Hucknall Road, Nottingham NG5 1PB, UK

Full list of author information is available at the end of the article
}

(c) The Author(s). 2018 Open Access This article is distributed under the terms of the Creative Commons Attribution 4.0 International License (http://creativecommons.org/licenses/by/4.0/), which permits unrestricted use, distribution, and reproduction in any medium, provided you give appropriate credit to the original author(s) and the source, provide a link to the Creative Commons license, and indicate if changes were made. The Creative Commons Public Domain Dedication waiver (http://creativecommons.org/publicdomain/zero/1.0/) applies to the data made available in this article, unless otherwise stated. 


\section{Background}

Soil is a complex mixture of minerals, live and dead organic matter, air, and water. The constituents of soils can enter the human body directly via geophagy or unintentional soil ingestion, airborne dust inhalation and absorption through (or through breaks in) the skin, or indirectly via the food chain (due to prior uptake by crop plants or consumption by livestock). Previous research suggests that adults in developed countries may inadvertently ingest between 23 and $625 \mathrm{mg}$ of soil each day [1]. Soils ubiquitously contain a range of inorganic elements produced through natural soil-forming processes, and as a legacy of inputs from human activity. Some, such as arsenic, cadmium, and lead, have long been recognized as harmful to human health in moderate to high doses [2], although the consequences of long-term low-level exposure remain unclear.

Existing research into the health impacts of soil constituents has tended to focus on geographic areas where abnormally high levels of exposure are observed. Studies of the effects of moderate or trace levels of potentially toxic elements are constrained by the commensurately smaller increases in the risk of adverse health outcomes they may produce. Furthermore, some adverse effects of soil contamination may only become apparent after extended periods of time, even in the presence of high levels of exposure. In consequence, it is often impractical or prohibitively expensive to recruit a sufficiently large (and statistically powerful) population of exposed individuals and to monitor their health over a sufficiently long period for such risks to become detectable.

For this reason, the safe maximum levels of many soil contaminants are not known. Existing official limits are typically based on backwards extrapolation from the known effects of extreme exposures or on inferences drawn from alternative sources of exposure [3].

The ability of epidemiological researchers to detect rare adverse effects of prescribed medications, and to study the causes of rare illnesses has been transformed in recent years by the development of large databases of routinely collected longitudinal data from United Kingdom health care services [4]. The use of such databases permits the construction of virtual study populations, with many years of follow-up, from a pool of millions of individual patients. The range of studies that can be carried out using such databases can be broadened through the linkage of individual patient records to other national data sources based on National Health Service patient identification numbers [5] or on patients' home addresses [6].

In recent years, the British Geological Survey (BGS) has carried out a comprehensive survey of the inorganic geochemistry of soils throughout England and Wales. We therefore carried out a linkage between these measurements and the medical records of over 7 million current and former patients from 377 primary care practices located throughout England and Wales, based on individuals' residential postcodes, creating a uniquely large and comprehensive database of soil exposures and health outcomes. To assess the representativeness and generalizability of the linked patient population, we carried out a validation comparing the range of exposures among our patients with those that would be expected based on known population distributions throughout the sampling area.

\section{Methods}

\section{Data sources}

BGS Geochemical Baseline Survey of the Environment (G-BASE)

The geochemical data used in this project derive from the BGS systematic national Geochemical Baseline Survey of the Environment (G-BASE) rural and urban soil information [7-9] and from a BGS re-analysis of the National Soil Inventory X-ray fluorescence spectrometry (NSI(XRFS)) samples [10, 11].

The two projects are closely comparable in their methods of collection: 0-15 cm deep with a sample support of $20 \mathrm{~m}$ and subsequently dried at $\sim 30{ }^{\circ} \mathrm{C}$ sieving to $<2 \mathrm{~mm}$ to exclude stones. The most significant difference between these surveys lies in the densities at which samples have been collected and the extent to which these surveys cover the land area of England and Wales. The rural G-BASE (collected from 1968 to 2007) data are concentrated in eastern and central England (Fig. 1) with additional samples from the Tamar catchment of South West England, with samples collected at 1 per $2 \mathrm{~km}^{2}$. Urban G-BASE samples have been collected (from 1992 to date) from the centers shown in Fig. 1 at a density of 4 per $\mathrm{km}^{2}$, making this the highest density of samples available in this study and the only systematic survey of urban soils in Britain. The NSI(XRFS) samples were collected (initially in the 1980s, with one-third of points resampled in the mid-1990s) at a density of 1 per $25 \mathrm{~km}^{2}$ over the whole of England and Wales and provide completeness of coverage of non-urban land areas, albeit at a coarser resolution than the rural G-BASE survey. These merged datasets give a total of 42,422 sample sites with data.

All of these data have been acquired by X-ray fluorescence spectrometry (XRFS) at the BGS laboratories using reference materials that allow bias and precision of the analyses to be monitored, providing a consistency and thus comparability between methods across all three datasets: we therefore jointly refer to these as G-BASE data in the rest of this paper. The use of XRFS is a true total analysis, as it requires no dissolution of the sample [12].

Data are available for 40 elements in total, and of these 15 were selected for linkage with the medical record data on the basis that they are major elements in soil (calcium, aluminium, and silicon), have a role to play in mobility of trace elements (iron [13]) in soil or are trace elements of key interest due to their known or suspected 


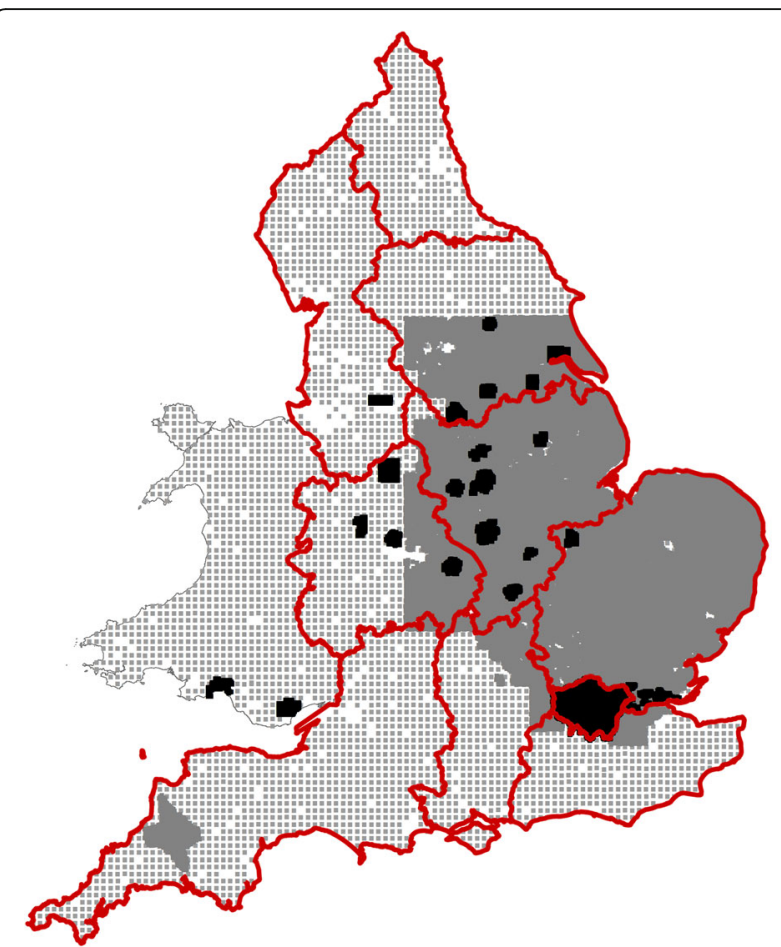

Fig. 1 Map of G-BASE sample locations in England and Wales. Black areas denote urban centres where samples are taken at a density of 4 per $\mathrm{km}^{2}$. Grey areas denote rural G-BASE areas, with a sampling density of 1 per $2 \mathrm{~km}^{2}$. Grey dots indicate locations of NSI(XRFS) samples, at an overall density of 1 per $25 \mathrm{~km}^{2}$. Red lines circumscribe the English Strategic Health Authority catchment areas. Contains Ordnance Survey data @ C Crown Copyright and database rights [2015]

effects on human health (arsenic [14], chromium [15], copper [16], lead [17], manganese [18], nickel [19], phosphorus [20], selenium [21], uranium [22], vanadium [23], and zinc [24]). We excluded cadmium from the final selection, in spite of its known toxicity in humans [25], because the concentrations observed in approximately $75 \%$ of G-BASE samples were below XRFS detection limits. Maps showing the variations in concentrations of the included elements throughout England and Wales are available in Additional file 1.

\section{The Health Improvement Network database}

Each individual in the UK population has the right to register with an NHS primary care practitioner who acts as their first port of call for most non-emergency medical assistance, providing onward referrals to secondary care facilities as necessary. The primary care practitioner is informed of diagnoses made and treatments given or initiated by secondary care institutions as a matter of routine. As a consequence of this gatekeeper role, the primary care medical record provides a comprehensive summary of each patient's medical history and interactions with the NHS.
The use of electronic medical record (EMR) software packages to create, store, and maintain primary care records has been widespread amongst UK practitioners since the early 1990s and has effectively been mandatory since the introduction in 2004 of the Quality and Outcomes Framework [26], an NHS pay-for-performance scheme which relies on analysis of EMRs to assess compliance with a range of record-keeping and care quality targets. The major EMR packages used by UK practitioners enable offsite backup facilities via a secure electronic link with the software provider.

These characteristics of UK EMR systems, and the relatively small number of packages in use, have facilitated the creation of several health research databases amalgamating data from multiple clinics to create large patient populations. The Health Improvement Network database is one such resource, containing the EMRs of over 10 million patients registered at over 500 practices throughout Great Britain and Northern Ireland, including 450 practices within the G-BASE coverage area. THIN has been extensively used in epidemiological research and the quality of recording has been validated for a wide range of important health outcomes (see e.g., [27-34]).

\section{Linkage process}

In order to preserve patient confidentiality, EMRs in THIN are stripped of details such as names, addresses, days and months of birth, and the exact locations of participating primary care practices prior to their transmission from the practice computer to the THIN data warehouse. Linkage of the G-BASE data to THIN records was therefore carried out within the participating practices themselves.

The G-BASE sample results and sampling locations were loaded into ArcGIS (Esri, Redlands, California, US) and used to interpolate each substance, with an inverse distance weighting (IDW) option with a search radius of $5 \mathrm{~km}$ and an output cell size of $1 \mathrm{~km}$. Polygons defining the English and Welsh postcode areas were overlaid, and a summary value (calculated as the concentration intersecting the point of the postcode polygon centroid) determined for each. Where there were no data within the search region, the result was returned as a missing value. Since there are more postcodes $(1,526,890)$ than sample sites, the distance from each postcode polygon centroid to the nearest sample site was calculated to establish the appropriateness of this method of joining the two data sources. This showed that $50 \%$ of the postcode centroids were $<1.3 \mathrm{~km}$, and $97 \%$ of postcodes $<5 \mathrm{~km}$, from an original sample site. These distances are a close match to the original sampling interval of the survey data (Fig. 1) used to derive the IDW raster surface of concentration values.

These data were output in text format and passed to The Health Improvement Network. Practices falling within 
the G-BASE coverage area were contacted individually and asked to participate in the linkage exercise. Where consent was given, a copy of the data was uploaded to the practice computer system via a secure electronic link, along with a script to be run by the practice manager. The script searched the G-BASE extract for the postcode of each patient's current (or last known, for deceased or deregistered patients) residential address and, where a match was found, transmitted the patient's unique identification code and the summary soil values (but, to preserve confidentiality, not the postcode) back to THIN. The patient identification codes were then used to link the soil values to the anonymized EMRs in the main THIN database.

\section{Validation}

Whilst the exact locations of patients and practices in THIN are unknown to us, the database does provide information on the Strategic Health Authority (SHA) to which each practice belongs. We therefore compared the levels of residential exposure experienced by patients registered in THIN with those that would be expected based on known population distributions in each SHA area.

Expected exposure distributions in each SHA were obtained by first estimating the population of each postcode area. The UK Office for National Statistics (ONS) postcode directory, which gives details of the SHA and census output area (OA) into which each postcode falls, was linked to 2011 OA census populations from the UK data service (formerly UKBorders) [35]. Each postcode within an $\mathrm{OA}$ was assumed to contain an equal proportion of the OA population. Where postcodes crossed an OA or SHA border, the postcode was randomly assigned to a single area.

The postcode-specific population estimates were then linked to the postcode-specific soil values obtained previously, and boxplots describing the expected exposure distributions in each SHA area were generated. Comparison boxplots were constructed describing exposures among all THIN patients who were alive and actively registered on the date of the 2011 census.

\section{Results}

\section{Practice participation and patient coverage}

At the time the data linkage process commenced, THIN contained information from 450 primary care practices in England and Wales. Of these, 395 were active contributors to THIN at the time the linkage commenced, with the remainder having left, merged, or closed at some point prior. 377 (95\%) of active practices agreed to participate in the linkage. The participation rate among practices in each SHA area is shown in Table 1. Participation was greatest in the West Midlands and South Central SHAs (both $100 \%)$ and lowest in Yorkshire \& Humber (78\%). The
Table 1 Number of practices participating in the linkage between The Health Improvement Network database and the Geological Baseline Survey of the Environment, by Strategic Health Authority area

\begin{tabular}{llll}
\hline $\begin{array}{l}\text { Strategic Health } \\
\text { Authority }\end{array}$ & $\begin{array}{l}\text { Participating } \\
\text { practices }\end{array}$ & $\begin{array}{l}\text { Active } \\
\text { practices }\end{array}$ & Participation rate (\%) \\
\hline East Midlands & 12 & 13 & 92 \\
East of England & 26 & 30 & 87 \\
London & 59 & 61 & 97 \\
North East & 12 & 13 & 92 \\
North West & 52 & 54 & 96 \\
South Central & 47 & 47 & 100 \\
South East Coast & 41 & 43 & 95 \\
South West & 45 & 46 & 98 \\
Wales & 36 & 39 & 92 \\
West Midlands & 40 & 40 & 100 \\
Yorkshire \& Humber & 7 & 9 & 78 \\
Total & 377 & 395 & 95 \\
\hline
\end{tabular}

conspicuously low rate in the latter case in fact represents only two refusals, the low percentage being a consequence of the small number of THIN practices in this region.

At the time of the linkage, THIN contained the medical records of 7.1 million patients currently or formerly registered at the 395 actively contributing practices. The average period of prospective computerized data recording (follow-up) was 6.75 years. 6.8 million (96\%) of these patients were registered at a practice that agreed to participate in the linkage. 6.3 million patients (93\%) from linkage practices lived in a postcode where at least one soil element level could be obtained from G-BASE, and 6.2 million patients (92\%) lived in an area where all 15 were available.

Of the patients with no soil measurements following the linkage process, 144,600 lived in a postcode listed in the postcode file uploaded to the practices, but for which there was no G-BASE coverage. For the remainder, the matching process failed entirely, indicating that the affected patients either had no postcode recorded in their medical records, an invalid or out-dated postcode, or a valid postcode not listed in the file uploaded to the practices (possibly because the postcode was newly-created).

Table 2 shows the matching levels broken down by SHA. The percentages of patients registered at linkage practices were similar to the percentages of practices that participated in the linkage (Table 1) suggesting that there was no marked difference in the sizes of the practices that declined to take part. The matching process was most successful in the East Midlands and the East of England, with 96 and $97 \%$ of patients respectively having the complete set of G-BASE measures, and least successful 
Table 2 Proportions of all patients ever registered at practices actively contributing data to The Health Improvement for whom partial (at least one element) or complete (all elements) soil measurements were obtained through linkage to the Geochemical Baseline Survey of the Environment (G-BASE)

\begin{tabular}{lllll}
\hline $\begin{array}{l}\text { Strategic } \\
\text { Health Authority }\end{array}$ & $\begin{array}{l}\text { Total patients at } \\
\text { active practices }\end{array}$ & $\begin{array}{l}\text { Patients at linkage } \\
\text { practices (\% of total) }\end{array}$ & $\begin{array}{l}\text { Patients with partial G-BASE data } \\
\text { (\% of patients at linkage practices) }\end{array}$ & $\begin{array}{l}\text { Patients with complete G-BASE data } \\
\text { (\% of patients at linkage practices) }\end{array}$ \\
\hline East Midlands & 212,395 & $198,085(93.3 \%)$ & $190,681(96.3 \%)$ & $190,679(96.3 \%)$ \\
East of England & 574,828 & $474,517(82.5 \%)$ & $462,008(97.4 \%)$ & $462,005(97.4 \%)$ \\
London & $1,208,044$ & $1,190,099(98.5 \%)$ & $1,000,246(84.0 \%)$ & $1,000,232(84.0 \%)$ \\
North East & 218,821 & $208,238(95.2 \%)$ & $175,302(84.2 \%)$ & $175,301(84.2 \%)$ \\
North West & 767,722 & $733,446(95.5 \%)$ & $660,898(90.1 \%)$ & $656,475(89.5 \%)$ \\
South Central & $1,069,029$ & $1,069,029(100.0 \%)$ & $1,040,055(97.3 \%)$ & $1,035,340(96.8 \%)$ \\
South East Coast & 873,765 & $845,650(96.8 \%)$ & $804,428(95.1 \%)$ & $804,367(95.1 \%)$ \\
South West & 763,658 & $752,735(98.6 \%)$ & $706,818(93.9 \%)$ & $706,817(93.9 \%)$ \\
Wales & 564,190 & $503,432(89.2 \%)$ & $485,619(96.5 \%)$ & $451,544(89.7 \%)$ \\
West Midlands & 716,592 & $716,592(100.0 \%)$ & $662,649(92.5 \%)$ & $633,347(88.4 \%)$ \\
Yorkshire \& Humber & 168,321 & $133,559(79.3 \%)$ & $131,448(98.4 \%)$ & $127,256(95.3 \%)$ \\
Total & $7,137,365$ & $6,825,382(95.6 \%)$ & $6,320,152(92.6 \%)$ & $6,243,363(91.5 \%)$ \\
\hline
\end{tabular}

in London and the North East $(84 \%$ complete in both cases.

The complete THIN database contains the details of all patients for whom an EMR has ever been created at a participating practice, even in cases where the patient died or deregistered some time ago. In order to carry out a like-for-like comparison between soil measurements in THIN and expectations based on the population distribution at the time of the 2011 census, it was necessary to restrict to patients alive and actively registered on this date. Among these patients the matching process was more successful, reflecting the increased likelihood that practitioners will hold a correct, up-to-date postcode for current or recent patients. 3.2 million patients were registered at actively participating practices. 3.0 million (96\%) were registered at a linkage practice. Complete and partial G-BASE measurements were available for 95\% (2.9 million) and $96 \%$ (2.9 million) of these patients respectively.

Sixty-six thousand three hundred twenty-seven patients lived in an area with no G-BASE coverage and 62,054 patients could not be matched. Table 3 shows the matching levels broken down by SHA. Again, the proportions of patients matched were similar to practice participation rates. The linkage was most successful in the East Midlands and the East of England (almost 100\% of patients having complete G-BASE data in both areas), and weakest in the North East (88\% complete) and London (89\% complete).

Table 3 Proportion of patients alive and registered on the date of the 2011 census at practices actively contributing data to The Health Improvement Network for whom partial (at least one element) or complete (all elements) soil measurements were obtained through linkage to the Geochemical Baseline Survey of the Environment (G-BASE)

\begin{tabular}{lllll}
\hline $\begin{array}{l}\text { Strategic } \\
\text { Health Authority }\end{array}$ & $\begin{array}{l}\text { Total patients at } \\
\text { active practices }\end{array}$ & $\begin{array}{l}\text { Patients at linkage } \\
\text { practices (\% of total) }\end{array}$ & $\begin{array}{l}\text { Patients with partial G-BASE data } \\
\text { (\% of patients at linkage practices) }\end{array}$ & $\begin{array}{l}\text { Patients with complete G-BASE data } \\
\text { (\% of patients at linkage practices) }\end{array}$ \\
\hline East Midlands & 102,970 & $96,498(93.7 \%)$ & $96,448(99.9 \%)$ & $96,448(99.9 \%)$ \\
East of England & 262,070 & $219,216(83.6 \%)$ & $219,038(99.9 \%)$ & $219,038(99.9 \%)$ \\
London & 443,050 & $436,073(98.4 \%)$ & $388,973(89.2 \%)$ & $388,970(89.2 \%)$ \\
North East & 105,225 & $99,672(94.7 \%)$ & $87,656(87.9 \%)$ & $87,656(87.9 \%)$ \\
North West & 375,752 & $361,339(96.2 \%)$ & $335,503(92.8 \%)$ & $333,132(92.2 \%)$ \\
South Central & 469,322 & $469,322(100.0 \%)$ & $467,804(99.7 \%)$ & $466,069(99.3 \%)$ \\
South East Coast & 388,040 & $369,537(95.2 \%)$ & $362,703(98.2 \%)$ & $362,676(98.1 \%)$ \\
South West & 357,656 & $353,201(98.8 \%)$ & $337,712(95.6 \%)$ & $337,711(95.6 \%)$ \\
Wales & 267,513 & $242,972(90.8 \%)$ & $240,679(99.1 \%)$ & $225,442(92.8 \%)$ \\
West Midlands & 333,920 & $333,920(100.0 \%)$ & $316,876(94.9 \%)$ & $303,968(91.0 \%)$ \\
Yorkshire \& Humber & 81,111 & $63,283(78.0 \%)$ & $63,260(100.0 \%)$ & $61,119(96.6 \%)$ \\
Total & $3,186,629$ & $3,045,033(95.6 \%)$ & $2,916,652(95.8 \%)$ & $2,882,229(94.7 \%)$ \\
\hline
\end{tabular}




\section{Comparison between the THIN population and the overall population}

Additional file 2 shows the results of the comparison between the observed levels of the linked measurements among the THIN population and those expected among the wider population of England and Wales. Overall, the patterns are very similar, with the most marked differences largely restricted to the Yorkshire \& Humber SHA, which has the both smallest number of participating practices and the smallest patient population. In particular, this region exhibits comparatively restricted ranges of exposures to arsenic, chromium, iron, manganese, and phosphorus.

\section{Discussion}

\section{Key findings}

By linking, at postcode level, the G-BASE and THIN databases, we were able to obtain residential soil element levels for patients at 95\% of English and Welsh practices, with complete geochemical data being available for $92 \%$ of patients within those practices. The levels associated with patients in the THIN database are in line with expectations based on the known population distributions in England and Wales, except in areas where there are few THIN practices.

\section{Strengths and limitations}

To our knowledge, the new linked resource is unique, providing unprecedented population size and statistical power to study the effects of elements in soil on human health. The data provide comprehensive, prospective recording of health outcomes across a population of over 6 million individuals offering, in principle, the potential to study the effects (whether adverse or beneficial) of any soil constituent present in the linked dataset on the risk of any medical condition diagnosed by or reported to primary care practitioners.

The additional health care and lifestyle details recorded in EMRs provide us with the ability to adjust for a wide range of potential confounding factors which may cluster geographically, as do the prior linkages of the THIN database to measures of area-level socioeconomic status, air pollution, and land use. The wide range of soil constituent measures we have linked will permit adjustment for the presence of other elements which may also modify the risk of outcomes of interest, and enable us to assess the extent of effect modification due to the presence of elements which may affect bioavailability (as in the case of iron and arsenic) [13].

The similarity of the soil constituent exposure levels observed among THIN patients to those that would be expected in the wider population suggests that studies using the linked resource are likely to produce generalizable results. Previous validation studies of the THIN database indicate that participants are representative of the population at large in terms of a range of sociodemographic measures [36].

There are a number of limitations that may affect the utility of the linked database in practice. The sampling resolution of the surveys in G-BASE may conceal focal areas of high variability in soil constituents. Local heterogeneity is generally greater in urban areas, but this is superimposed upon systemically increased concentrations associated with the impact of urbanisation for elements such as lead and copper [37, 38]. In urban areas, where the THIN population is concentrated, sampling density is high (4 per $\mathrm{km}^{2}$ ) and work carried out during the completion planning for G-BASE suggests that improvements in estimate precision above the 1 per $2 \mathrm{~km}^{2}$ level may be relatively small [39], although this will vary from element to element.

Uncertainties always exist in the interpolation of values between points of measured concentration to make predictions at unsampled locations. We used the inverse distance weighting method as it is a relatively straightforward and widely understood approach that produces estimates primarily determined by the closest available sample site. Point estimates at the postcode centroid (rather than an alternative such as an average of all points within a postcode) were considered sufficient as UK postcode areas are small (especially relative to the distance between sampling sites): in urban areas each typically represents a small section of a street, or even a single large apartment building) and contains an average of 15 (range 1-100) individual mail delivery addresses [40]. More sophisticated techniques (such as those based on machine learning) which incorporate information from additional mapping layers have been shown to improve precision in subsets of the G-BASE data [41], however this is an ongoing area of research and such methods have not yet been applied or validated across the full survey area.

We cannot be certain that the presence of raised levels of a contaminant in the soil in the area where each patient lives directly translates into increased exposure among those patients; where patients work a long distance from home, consume little locally-produced produce, seldom engage in outdoor activities such as sports or gardening, or live in focal areas of severe contamination, the true exposure level may be markedly different. The presence of a substantial number of such individuals in the THIN population would tend to introduce random error. This would typically manifest as a null bias, so whilst it is unlikely to lead to the false identification of an increased risk, the magnitude of a true risk might be underestimated. The large size of the THIN population (and concomitant statistical power) will reduce the impact of such bias on our ability to detect raised risks, even in cases where we are unable to accurately quantify them. 
The participation rate among practices in the Yorkshire and Humber SHA was low, which may restrict our ability to draw inferences about the risks experienced by patients in this area. In addition, there is a known bias towards arable land within the NSI(XRFS) sample collection areas (the survey was initially carried out to help assess agricultural potential). This issue primarily affects West Wales, where known examples of industrial land contamination are not detectable in the NSI(XRFS) dataset $[37,42]$. We are unable to distinguish between different compound forms of the elements included in the linkage, which may be problematic where toxicity or effects on bioavailability differ [43]. For example, different forms of iron are known to differentially affect the bioavailability of arsenic in soils [13]. It is likely, however, to be possible to at least partially adjust for this at area level; whilst we do not know the exact locations of patients or practices in the linked dataset, we do know to which Strategic Health Authority area each practice belongs, and the ratios between ironstones and other mineral forms of iron differ substantially between these areas [44].

Whilst the THIN data are longitudinal, the G-BASE data are (although collected over an extended period) effectively cross-sectional, and the linkage has been carried out at a single point in time. The exposure levels assigned to each individual may not, therefore, be representative over the entire duration of follow-up. Previous research suggests that levels of most of the soil constituents included in the linkage are driven by (generally slow) geological processes and that levels are relatively stable over time, except in areas and for elements where there are significant ongoing inputs from industrial or agricultural activities [45].

The linked measures are unlikely to accurately reflect long-term exposure for patients who have only been registered for a short time, however it should be possible to address this issue by carrying out sensitivity analyses restricted to patients who have been continuously registered for an extended period. In addition, THIN is updated quarterly, so the duration of follow-up available for the patients included in the linkage will increase over time. Movement of patients away from (and registration of new participants into) participating practices will, over time, reduce the proportion of patients for whom soil measures are available, requiring the linkage to be repeated. The patients who leave the database will be more likely to be those who are in highly mobile sociodemographic groups, somewhat reducing the demographic representativeness of the linked population, but at the same time preferentially removing those for whom point estimates of exposure are least likely to reflect lifetime exposure.

When linking geospatial and medical datasets there is, in each case, a need to make compromises in order to preserve patient confidentiality. The THIN/G-BASE linkage demonstrates a viable approach that provides high quality, individual-level data on a very large number of patients at the cost of limiting our knowledge of patient locations and the number of geochemical variables we were able to link (to avoid producing unique combinations which would make postcodes and patients readily identifiable). It is unlikely that linkages providing spatial information in sufficient detail for risk mapping and GIS analysis, or that incorporate richer information about soils (e.g., more constituents, or details of other soil characteristics that may influence exposure or bioavailability) would receive ethical approval in most jurisdictions unless either explicit patient consent was obtained (limiting the feasibility of assembling a large research population), or summary data on population health was used in place of individual patient records. This situation may improve in the near future, however, as emerging techniques for secure multi-party statistical analysis [46] may enable multiple data-holders to carry out rich joint analyses without explicitly linking or sharing their datasets with one another and creating confidentiality concerns in the process.

\section{Arrangements for access}

Given the wide potential scope for studies using the linked database, it is our hope that external researchers will make use of it in their research and we have put in place a process to enable wider access. Both the THIN and G-BASE components of the linked data are subject to licensing restrictions, and ethical approval is required from the THIN Scientific Research Committee before data extracts can be made available. Parties interested in obtaining data for research projects should contact IQVIA (https:// www.iqvia.com/locations/uk-and-ireland/thin) in the first instance.

\section{Conclusions}

The linkage of millions of primary care electronic medical records of patients throughout England and Wales to individual-level estimates of residential soil element exposure opens new avenues for research in environmental public health, providing a cohort with considerable statistical power to investigate even minor effects across an extremely wide range of health outcomes. Our findings suggest that, with appropriate adjustment, results should be generalizable to and representative of the wider English and Welsh population.

\section{Additional files}

Additional file 1: Maps of soil element levels by United Kingdom Strategic Health Authority area. Contains Ordnance Survey data (c) Crown Copyright and database rights [2015]. (DOCX 33519 kb) 
Additional file 2: Observed range of concentrations of 15 linked constituent elements in the residential soils of patients enrolled in The Health Improvement Network database on the date of the 2011 UK census, by Strategic Health Authority, and comparison with the expected range of concentrations in the residential soils of the entire Strategic Health Authority populations, estimated using 2011 Census population distributions. Boxes indicate interquartile ranges, midlines indicate median values and whiskers are drawn to the upper and lower adjacent values. (PDF $87 \mathrm{~kb}$ )

\section{Abbreviations}

BGS: The British Geological Survey, United Kingdom; EMR: Electronic medical record; G-BASE: The British Geological Survey systematic national Geochemical Baseline Survey of the Environment; NHS: The United Kingdom National Health Service; NSI (XRFS): The National Soil Inventory X-Ray fluorescence spectrometry sample set; OA: United Kingdom census 2011 output area; SHA: (English) Strategic Health Authority; THIN: The Health Improvement Network database; UK: The United Kingdom of Great Britain and Northern Ireland; XRFS: X-ray fluorescence spectrometry

\section{Funding}

The cost of linking the THIN database to GBASE was supported by an internal grant from the School of Health Sciences, University of Nottingham. The British Geological Survey is part of the UK Natural Environment Research Council.

\section{Availability of data and materials}

THIN-GBASE linked database: The data that support the findings of this study are available from IQVIA but restrictions apply to the availability of these data, which were used under license for the current study, and so are not publicly available. Data are however available from the authors upon reasonable request and with permission of IQVIA. https://www.iqvia.com/ locations/uk-and-ireland/thin.

ONS Postcode Directory: The data that support the findings of this study are available from the UK National Statistics Geoportal at http:// geoportal.statistics.gov.uk/ datasets?q=ONS\%20Postcode\%20Directory\%20(ONSPD)\&sort=name 2011 census populations: The data that support the findings of this study are publicly available from the UK Office for National Statistics: http:// www.nomisweb.co.uk/output/census/2011/ks101ew_2011_oa.zip

\section{Authors' contributions}

All authors contributed to the design of the study. LA carried out the data management work to prepare GBASE data for linkage to THIN. JG coordinated the linkage between THIN and GBASE data, carried out the validation analyses, and drafted the manuscript. All authors contributed to the interpretation of the results and revising the manuscript for intellectual content. All authors read and approved the final manuscript.

\section{Ethics approval and consent to participate}

The collection of data for The Health Improvement Network database (THIN) was approved by the South West Research Ethics Committee (reference number 07/H1102/103). Separate REC approval is not required for postcode linkages to geographic data sources. The linkage between THIN and the Geochemical Baseline Survey of the Environment was internally approved by IQVIA (the providers of the THIN database) and the British Geological Survey.

\section{Consent for publication}

Not applicable

\section{Competing interests}

The authors declare that they have no competing interests.

\section{Publisher's Note}

Springer Nature remains neutral with regard to jurisdictional claims in published maps and institutional affiliations.

\section{Author details}

'Division of Epidemiology \& Public Health, School of Medicine, University of Nottingham, Clinical Sciences Building Phase II, City Hospital, Hucknall Road Nottingham NG5 1PB, UK. ${ }^{2}$ Centre for Environmental Geochemistry, British
Geological Survey, Nicker Hill, Keyworth, Nottingham NG12 5GG, UK. ${ }^{3}$ Environmental Geochemistry Baselines Group, British Geological Survey, Nicker Hill, Keyworth, Nottingham NG12 5GG, UK. ${ }^{4}$ Centre for Evidence Based Health Care, School of Health Sciences, University of Nottingham, Queen's Medical Centre, Nottingham NG7 2HA, UK.

Received: 21 July 2016 Accepted: 19 June 2018

Published online: 16 July 2018

\section{References}

1. Davis S, Mirick DK. Soil ingestion in children and adults in the same family. J Expo Sci Environ Epidemiol. 2006;16:63-75. https://doi.org/10.1038/sj.jea.7500438.

2. Cooksey C. Health concerns of heavy metals and metalloids. Sci Prog. 2012; 95:73-88. https://doi.org/10.3184/003685012X13286247093244.

3. Hosford M. Human health toxicological assessment of contaminants in soil: using science to create a better place. Bristol: Environment Agency; 2008.

4. Harpe SE. Using secondary data sources for pharmacoepidemiology and outcomes research. Pharmacotherapy. 2009;29:138-53. https://doi.org/10. 1592/phco.29.2.138.

5. Mathur R, Bhaskaran K, Chaturvedi N, Leon DA, vanStaa T, Grundy E, et al. Completeness and usability of ethnicity data in UK-based primary care and hospital databases. J Public Health. 2013:fdt116. https://doi.org/10.1093/pubmed/fdt116.

6. Sharma A, Lewis S, Szatkowski L. Insights into social disparities in smoking prevalence using mosaic, a novel measure of socioeconomic status: an analysis using a large primary care dataset. BMC Public Health. 2010;10:755. https://doi.org/10.1186/1471-2458-10-755.

7. Fordyce FM, Brown SE, Ander EL, Rawlins BG, O'Donnell KE, Lister TR, et al. GSUE: urban geochemical mapping in Great Britain. Geochem Explor Environ Anal. 2005:5:325-36.

8. Johnson CC, Breward N, Ander EL, Ault L. G-BASE: baseline geochemical mapping of Great Britain and Northern Ireland. Geochem Explor Environ Anal. 2005;5:347-57. https://doi.org/10.1144/1467-7873/05-070.

9. Flight DMA, Scheib AJ. Soil geochemical baselines in UK urban centres: the GBASE project. Mapping the chemical environment of urban areas. Oxford: Wiley; 2011. p. 186-206. Available: https://doi.org/10.1002/9780470670071.ch13

10. Loveland PJ, McGrath SP, editors. The soil geochemical atlas of England and Wales. Glasgow: Blackie Academic \& Professional; 1992.

11. Rawlins BG, McGrath SP, Scheib AJ, Breward N, Cave M, Lister TR, et al. The advanced soil geochemical atlas of England and Wales [Internet]. British Geological Survey: Nottingham; 2012. Available: http://resources.bgs.ac.uk/ ebooks/AdvancedSoilGeochemicalAtlasEbook/pubData/source/Advanced\% 20Soil\%20Geochemical\%20Atlas\%20of\%20England\%20and\%20Wales.pdf.

12. Ingham MN, Vrebos BAR, Gilfrich JV. High productivity geochemical XRF analysis. advances in X-ray analysis: proceedings of the annual conference on application of X-ray analysis / edited by William M Mueller and Marie Fay; sponsored by University of Denver, Denver Research Institute; 1994. p. 717-24.

13. Hartley W, Edwards R, Lepp NW. Arsenic and heavy metal mobility in iron oxide-amended contaminated soils as evaluated by short- and long-term leaching tests. Environ Pollut. 2004;131:495-504. https://doi.org/10.1016/j. envpol.2004.02.017.

14. Argos M, Ahsan H, Graziano JH. Arsenic and human health: epidemiologic progress and public health implications. Rev Environ Health. 2012;27:191-5. https://doi.org/10.1515/reveh-2012-0021.

15. Barceloux DG. Chromium. J Toxicol Clin Toxicol. 1999;37:173-94.

16. Barceloux DG. Copper. J Toxicol Clin Toxicol. 1999;37:217-30.

17. Tong S, von Schirnding YE, Prapamontol T. Environmental lead exposure: a public health problem of global dimensions. Bull World Health Organ. 2000; 78:1068-77

18. Barceloux DG. Manganese. J Toxicol Clin Toxicol. 1999:37:293-307.

19. Barceloux DG. Nickel. J Toxicol Clin Toxicol. 1999;37:239-58.

20. Takeda E, Yamamoto H, Yamanaka-Okumura H, Taketani Y. Dietary phosphorus in bone health and quality of life. Nutr Rev. 2012;70:311-21. https://doi.org/10.1111/j.1753-4887.2012.00473.x.

21. Barceloux DG. Selenium. J Toxicol Clin Toxicol. 1999:37:145-72.

22. Brugge $D$, Buchner $V$. Health effects of uranium: new research findings. Rev Environ Health. 2011:26:231-49.

23. Barceloux DG. Vanadium. J Toxicol Clin Toxicol. 1999;37:265-78

24. Barceloux DG. Zinc. J Toxicol Clin Toxicol. 1999:37:279-92.

25. Kah M, Levy L, Brown C. Potential for effects of land contamination on human health. 1.The case of cadmium. J Toxicol Environ Health B Crit Rev. 2012;15:348-63. https://doi.org/10.1080/10937404.2012.705107. 
26. Introduction to QOF [Internet]. Available: http://webarchive.nationalarchives. gov.uk/20100402204538/http://www.ic.nhs.uk/statistics-and-data-collections/ supporting-information/audits-and-performance/the-quality-and-outcomesframework/qof-information/introduction-to-qof. Cited 19 May 2012

27. Bourke A, Dattani H, Robinson M. Feasibility study and methodology to create a quality-evaluated database of primary care data. Inform Prim Care. 2004;12:171-7.

28. Meal A, Leonardi-Bee J, Smith C, Hubbard R, Bath-Hextall F. Validation of THIN data for non-melanoma skin cancer. Qual Prim Care. 2008;16:49-52.

29. Ruigómez A, Martín-Merino E, Rodríguez LAG. Validation of ischemic cerebrovascular diagnoses in the health improvement network (THIN). Pharmacoepidemiol Drug Saf. 2010;19:579-85. https://doi.org/10.1002/pds.1919.

30. Denburg MR, Haynes K, Shults J, Lewis JD, Leonard MB. Validation of The Health Improvement Network (THIN) database for epidemiologic studies of chronic kidney disease. Pharmacoepidemiol Drug Saf. 2011;20:1138-49. https://doi.org/10.1002/pds.2203.

31. Seminara NM, Abuabara K, Shin DB, Langan SM, Kimmel SE, Margolis D, et al. Validity of The Health Improvement Network (THIN) for the study of psoriasis. Br J Dermatol. 2011;164:602-9. https://doi.org/10.1111/j.1365-2133. 2010.10134.x.

32. Martín-Merino E, Fortuny J, Rivero E, García-Rodríguez LA. Validation of diabetic retinopathy and maculopathy diagnoses recorded in a U.K. primary care database. Diabetes Care. 2012;35:762-7. https://doi.org/10.2337/dc11-2069.

33. Hall GC. Validation of death and suicide recording on the THIN UK primary care database. Pharmacoepidemiol Drug Saf. 2009;18:120-31. https://doi. org/10.1002/pds. 1686.

34. Meropol SB, Metlay JP. Accuracy of pneumonia hospital admissions in a primary care electronic medical record database. Pharmacoepidemiol Drug Saf. 2012;21:659-65. https://doi.org/10.1002/pds.3207.

35. UK Data Service Census Home [Internet]. Available: https://census. ukdataservice.ac.uk. Cited 19 Feb 2014

36. Blak BT, Thompson M, Dattani H, Bourke A. Generalisability of The Health Improvement Network (THIN) database: demographics, chronic disease prevalence and mortality rates. Inform Prim Care. 2011;19:251-5.

37. Ander EL, Johnson CC, Cave MR, Palumbo-Roe B, Nathanail CP, Lark RM. Methodology for the determination of normal background concentrations of contaminants in English soil. Sci Total Environ. 2013;454-455:604-18. https://doi.org/10.1016/j.scitotenv.2013.03.005.

38. Rawlins BG, Lark RM, O'Donnell KE, Tye AM, Lister TR. The assessment of point and diffuse metal pollution of soils from an urban geochemical survey of Sheffield, England. Soil Use Manag. 2005;21:353-62. https://doi. org/10.1079/SUM2005335.

39. Johnson CC, Flight DMA. Completion plan for the Geochemical Baseline Survey of the Environment (G- BASE) [Internet]. Keyworth: British Geological Survey; 2011. Available: http://nora.nerc.ac.uk/id/eprint/19492/1/ CompletionPlan_IR11065.pdf

40. Ordnance Survey http://www.ordnancesurvey.co.uk/oswebsite/support/ contact-us.html. Postcode Unit [Internet]. [cited 31 Jan 2017]. Available: http://data.ordnancesurvey.co.uk/ontology/postcode/PostcodeUnit.

41. Kirkwood C, Cave M, Beamish D, Grebby S, Ferreira A. A machine learning approach to geochemical mapping. J Geochemical Exploration. 2016;167. https://doi.org/10.1016/j.gexplo.2016.05.003.

42. Ander L, Cave MR, Johnson CC. Normal background concentrations of contaminants in the soils of Wales: exploratory data analysis and statistical methods [Internet]. 2013 [cited 10 Apr 2014]. Available: http://nora.nerc.ac. uk/id/eprint/501566/1/CR12107N.pdf.

43. Appleton JD, Cave MR, Wragg J. Modelling lead bioaccessibility in urban topsoils based on data from Glasgow, London, Northampton and Swansea, UK. Environmental Pollution. 2012;171:265-72. https://doi.org/10.1016/j. envpol.2012.06.018.

44. Appleton JD, Cave MR, Wragg J. Anthropogenic and geogenic impacts on arsenic bioaccessibility in UK topsoils. Science of The Total Environment. 2012;435-436:21-29.

45. Atteia O, Dubois J-P, Webster R. Geostatistical analysis of soil contamination in the Swiss Jura. Environ Pollut. 1994;86:315-27.

46. Shi H, Jiang C, Dai W, Jiang X, Tang Y, Ohno-Machado L, et al. Secure MultipArty Computation Grid LOgistic REgression (SMAC-GLORE). BMC Med Inform Decis Mak. 2016;16:89.

\section{Ready to submit your research? Choose BMC and benefit from:}

- fast, convenient online submission

- thorough peer review by experienced researchers in your field

- rapid publication on acceptance

- support for research data, including large and complex data types

- gold Open Access which fosters wider collaboration and increased citations

- maximum visibility for your research: over $100 \mathrm{M}$ website views per year

At BMC, research is always in progress.

Learn more biomedcentral.com/submissions 